\section{THE PHYSICAL SOCIETY'S EXHIBITION.}

THE fifth annual exhibition, which was held by the Physical Society of London at the Imperial College of Science and Technology last week, was marked by some pleasing innovations. Hitherto the exhibition has been limited to the evening only, but on this occasion it was open also in the afternoon, and this extension of time was evidently appreciated. Experimental lectures were also introduced. Thus many visitors must have welcomed the opportunity of seeing once again the beautiful and wellknown experiments on soap bubbles by Prof. C. V. Boys, F.R.S., as they have not been seen during the last ten or fifteen years. In the evening Prof. S. P. Thompson, F.R.S., showed the remarkable effects obtained by combining mica and selenite viewed under polarised light.

Turning to the exhibits themselves, we may remark that there were about forty exhibitors, and for this reason it is impossible to do more than give a brief reference to some of the more interesting and novel exhibits in the space at our disposal. In the subject of mechanics, in its broadest sense, Mr. W. V. Gilbert's anticlastic levers, shown by Messrs. Strange and Graham, received the most attention. The device is known by the trade name of "Vilcars," and enables a movement in a given plane to produce a movement in a plane at right angles, although no joints or complicated links are used for producing this change in the direction of motion.

Among other mechanical devices we may mention the Wimperis accelerometer, shown by Messrs. Elliott Bros. (see NATURE, December 2, p. 139). The acceleration is indicated by a pointer, which moves on a scale suitably graduated. The indication is effected by an eccentrically placed copper disc which is controlled by a hairspring and is magnetically damped. By a special gear and balance weight the disc is compensated so that the instrument is affected only by acceleration in one direction, which is indicated by an arrow on the dial. A simpler type of instrument is that due to Mr. A. P. Trotter, and shown by Messrs. Everett, Edgcumbe and Co. This consists simply of a curved glass tube nearly filled with liquid, and is best described as a spirit-level of extravagant curvature. When subjected to acceleration along its length the position of the bubble varies according to the acceleration. Obviously it may be used equally for measuring gradients.

The principle of the diffusion of gases is brought into practical use in the gas-leakage indicator shown by the Cambridge Scientific Instrument Co. An elastic metal chamber is closed by a porous tile, so that the pressure within it increases when the instrument is brought into an atmosphere containing light gas, such as coal gas. The pressure is shown by a pointer, the motion of which is an indication of the presence of gas.

There was a good display of optical apparatus, including microscopes, cameras, and photometers. Among the latter may be mentioned the daylight illumination photometer due to Mr. A. P. Trotter, and exhibited by Messrs. Everett, Edgcumbe and Co. In testing the illumination of a room by daylight, an absolute figure in, say, candlefeet is not of value by itself, because it depends upon the brightness of the day on which the measurement is made This difficulty is overcome by using a vertical tube placed over the screen which receives the illumination to be measured. The instrument is first placed where a clear view of the zenith is obtained, and a stop is inserted in the tube so as to cut down the illumination to a convenient figure. A measurement is then made in the room where desired, the tube having been removed. The stops are so proportioned that the true ratio of the illumination in the room to that in the open is readily obtained. As examples of such measurements the makers mention that the ratio over the Speaker's chair in the House of Commons is 0.0009 , and that in the British Museum reading room 0.00 -

Electrical exhibits were by far the most numerous, and among these perhaps the most interesting was the application of Abraham's rheograph (shown by the Cambridge Scientific Instrument Co.) to throw on the screen a hysteresis loop. It will be remembered that in the rheograph a light aluminium frame is suspended in a permanent magnetic field, and forms the secondary of a small transformer. The controlling and damping forces are made relatively unimportant, so that the deflection becomes proportional to the current or potential difference under observation. On the present occasion two vibrators were arranged at right angles, one to give a deflection proportional to $\mathbf{B}$ and the other to $\mathbf{H}$. A beam of light being reflected first from one and then from the other therefore gave a hysteresis loop, which appeared quite steady upon the screen.

The same firm showed Dr. C. V. Drysdale's slip meter, which, although it has been in use for some years at the Northampton Institute, has not, so far, been generally available. A circular card, on which certain geometric figures are printed, is fixed to the shaft of the machine under test, and is observed through a stroboscopic disc. The latter is driven frictionally by a conical roller, which in turn is driven by a small synchronous motor. By moving the disc along the roller its speed is varied, and when the geometric figures on the card appear stationary the speed can be read off on the graduated leading screw which controls the position of the disc. This part of the apparatus is quite smail and compact. Depending on the arrangements used, speed, frequency or slip can be determined.

Messrs. Snell and Tinsley showed one of Dr. C. V. Drysdale's potentiometers for alternating currents, the difficulty of phase difference being eliminated by a "phase shifter," by which the phase of the current in the potentiometer wire is made to coincide with that of the pressure to be measured. A rotary field is produced in the phase shifter by splitting up a single-phase current into two in quadrature.

Duddell's vibration galvanometer, which is a modified oscillograph, was shown by Messrs. Nalder Bros. and Co. Messrs. J. J. Griffin and Sons exhibited Mr. Tucker's high. potential primary battery; it is compact in form, and papears to give its Iooo volts with a minimum of trouble. Mr. F. Harrison Glew showed a radium collector for atmospheric electricity. This consists of a metal spiral coated with insoluble radium salts; it is suspended in an elevated position from a weather-proof insulator, and as the radium ionises the air around it the wire acquires the potential of the atmosphere, and gives an indication on an electroscope.

Visitors also had an opportunity of seeing one of the latest methods of transmitting photographs electrically, as exemplified in the apparatus of $\mathrm{Mr}$. T. Thorne Baker, shown by the Daily Mirror. Prof. Korn's method, with selenium cells, has reached a stage of some perfection, but the smallness of the currents available in such a method introduces difficulties. There is thus a tendency to use rather more mechanical methods. In Mr. Baker's apparatus, photographs are printed on fish-glue upon lead foil, and lines are drawn across this so as to expose the lead. The style comes into contact more or less with the lead, depending upon the density of the image, and thus allows current to flow into the line. At the receiver the picture apnears on suitably prepared paper by electrolytic action, and the results seem to be very satisfactory.

The exhibits we have enumerated by no means exhaust all that was of interest, but want of space renders a complete survey impossible.

\section{EXPERIMENTS ON COMPOUND STRESS.}

TWO papers dealing with experiments on compound stress were read at the Institution of Mechanical Engineers on Friday, December I7. The first of these, by Mr. William Mason, of the University of Liverpool, gave the results of tests made by the author on mild steel tubes, and included tests made in simple compression, in simultaneous compression and hoop tension, in simple axial tension, simultaneous axial and hoop tension, simple axial compression, and simultaneous axial and hoop compression. Two sizes of tubes were used, viz. 3 inches bore and 2.75 inches bore, of thickness about 0.08 and 0.128 inch respectively. The larger tubes were cold-drawn, and the others were hot-drawn. Some of the tests were made on the tubes unannealed, in others the tubes were annealed. Extensometers of the Ewing type were used in measuring NO. 2095, VOL. 82] 
the strains. The testing machine employed was the roo-ton Buckton machine in the Walker Engineering Laboratory. Hoop tension and compression were obtained by applying hydraulic pressure to the inside and outside of the tubes respectively; in the latter case a special jacket surrounded the tube under test. The experiments show an approximate agreement between the maximum shear stress at the yield point in compression and the yield-point stress in pure shear, the mean difference in the tests of annealed specimens being about 3 per cent. It appears, then, that mild steel in compression yields by shearing; and, to a first approximation, the value of this shear stress is independent of any normal compressive stress on the planes of the slide.

The second paper was contributed by Mr. C. A. M. Smith, of the East London College, University of London. Solid mild steel test specimens were used under combined tension and torsion, and also under combined compression and torsion. The 50-ton machine at the college was used, and the strains were measured by means of the author's sphingometer, by means of which readings are obtained on three planes at 120 degrees. The results obtained give further confirmation of Guest's law for mild steel. The author's remarks regarding the difficulty of obtaining axial application of the load, both with pull and push, were of special interest. Ordinary wedge grips are of little use in securing this; even spherical seatings are bad. Sphingometer readings with the latter show great divergence from regularity in the strains on three planes, although the means are perfectly regular. Often in a test the ball joints slip into new bearing positions, thus producing a new eccentricity of the load. These facts emphasise the necessity of employing an instrument of the sphingometer type in tests of a scientific character for loads within the yield point.

\section{THE PARASITES OF THE GROUSE.}

SOME valuable results of the work of the Grouse Disease Inquiry Commission are published by Dr. A. E. Shipley, F.R.S., in a series of papers on the parasites of the red grouse (Proc. Zool. Soc. Lond., r9o9, pp. 309368 , plates $x x x v .-1 x$.$) , in which the ectoparasites, the$ thread-worms, and the tape-worms are successively described and illustrated.

Ninety per cent. of the birds examined were infested with two species of Mallophaga (Goniodes tetraonis and Nirmus cameratus) which feed on the barbules of the feathers. "The number on each bird is to some extent an inverse measure of their health." Though not a parasite, the larva of the common dung-fiy (Scatophaga stercoraria) is described and excellently figured-a noteworthy contribution to the scanty literature on larval Diptera-because it was hoped that these maggots, which are found in numbers among the droppings of the grouse, might prove to be intermediate hosts for the grouse tapeworms; the results, however, were entirely negative. Witl the same object in view, the crops of many grouse were examined, and although gamekeepers and sportsmen believe that these birds eat no insects, their animal food was, in fact, found to be "fairly abundant and very varied," comprising caterpillars of moths and saw-flies, froghoppers and Diptera, spiders and slugs. Although no bladder-worms were found by these investigations, Dr. Shipley has incidentally thrown light on the feeding habits of the grouse, and has shown that mere external observation in such questions is often to be distrusted.

The grouse tape-worms, the cysticercus stages of which are thus still unknown, comprise a larger species (Davainea urogalli) and a smaller one (Hymenolepis microps). This latter, "so transparent when alive as almost to be invisible," is nevertheless very abundant in the duodenum, where its presence appears to be often fatal to the birds, so that it is a far more serious pest than its larger companion.

Of the Nematoda that infest the grouse, Trichosoma longicolle and Trichostrongylus pergracilis are the most important, and the latter of these, at least, requires no intermediate host for its development. By soaking heather and then centrifuging the drawn-off water, Dr. Shipley NO. 2095 , VOL. 82$]$ showed that "heather is, so to speak, crawling with thread-worms "; the means by which the nematode larvæ, hatched from eggs passed out of the birds' intestines, enter the food canal of new hosts is thus plain. Another fact of interest is the presence of larval thread-worms in the lungs and liver; these are believed to be derived from eggs hatched while still in the intestine of their parents' host-bird, and to wander through the latter's body. Readers who have followed Dr. Shipley's recent suggestions as to the importance of parasitic worms in certain human diseases will be prepared for his belief that these wandering larval nematodes may be responsible for pathological conditions in the organs of the grouse.

G. H. C.

\section{UNIVERSITY AND EDUCATIONAL INTE LLIGENCE.}

CAMBRIDGE.-The general board of studies has appointed $\mathrm{Mr}$. L. A. Borradaile to be university lecturer in zoology from January I, 1910, to September 30, 1914.

It is proposed, in accordance with the recommendation of the special board for moral science, to appoint a syndicate to make arrangements for the building of a laboratory of experimental psychology.

DR. J. L. Simonsfe, assistant lecturer and demonstrator i. chemistry in the University of Manchester, has been appointed professor of chemistry in the University of Madras, and Dr. A. Holt has succeeded him at Manchester.

A LECTURE by some man eminent in letters, science, or art, to be delivered annually in the Lent term, has been established at Queen's College, London. Her Majesty the Queen, patron of the college, has allowed it to be called the Queen's lecture.

UNDER the Irish Universities Act, 1908, graduates of the Royal University of Ireland may be registered as graduates of the National University of Ireland. We are asked to announce that as the first meeting of Convocation must take place within six months from the date of the dissolution of the Royal University of Ireland, it is very advisable that application for registration as graduates should be made without delay. All information may be obtained from Dr. Joseph McGrath, registrar of the University, the National University of Ireland, Dublin.

Courses of afternoon lectures on aëronautics will be held after Christmas at the Imperial College of Science and Technology. Sir George Greenhill, F.R.S., will lecture on the dynamics of an aëroplane; Mr. H. R. A. Mallock, F.R.S., on fluid resistance; and Colonel H. C. L. Holden, F.R.S., on light petrol motors for aërial work. The courses will begin respectively about the middle of January, the early part of February, and after Easter. Research scholarships will be awarded by the college to advanced students desirous of undertaking research work in scientific problems connected with aëronautics. The scholarships are to be tenable for one year at the Imperial College, and provision may be made for part of the work to be undertaken at the National Physical Laboratory. Scholars will be entitled to free admission to the college and to a maintenance allowance.

THE next annual conference of teachers arranged by the London County Council will be held on January 6-8 inclusive at Birkbeck College, Chancery Lane, London. Among the subjects for discussion, we notice that during the afternoon of the first day the training of engineers will be dealt with. Sir William White, K.C.B., will preside, and addresses will be delivered by Prof. D. S. Capper on the training of engineers, by Dr. R. M. Walmsley on the sandwich system as applied to day engineering students, and by Mr. R. Bunting on higher elementary education and the preliminary training of engineers. The next afternoon Sir Lauder Brunton will preside, and the teaching of domestic economy will be discussed. Mr. John Wilson will deliver an address on the correlation between the teaching of domestic economy and experimental science. Other subjects of discussion will be:--the organisation of higher schools; the teaching of number; methods of teaching in schools for the mentally 